\title{
Soil organic carbon sequestration according to two Geoset long-term field experiments in the Moscow region
}

\author{
K.O. Prokopyeva ${ }^{1 * 1}$, V.A. Romanenkov ${ }^{1,2}$, N.K. Sidorenkova ${ }^{3}$, and P.V. Krasilnikov ${ }^{l}$ \\ ${ }^{1}$ Lomonosov Moscow State University, 119991, Leninskie Gory, 1, Moscow , Russia \\ ${ }^{2}$ All-Russian Research Institute of Agrochemistry named after D.N. Pryanishnikov, 127550, \\ Pryanishnikova str., 31a, Moscow, Russia \\ ${ }^{3}$ RSAU-MAA named after K.A.Timiryazev, 127550, Timiryazevskaya str., 49, Moscow, Russia
}

\begin{abstract}
The feasibility of implementing the "4 ppm" initiative, which assumes an annual increase in organic carbon stocks of agricultural soils in the layer $0-40 \mathrm{~cm}$, was estimated with the dynamic carbon model RothC in two long-term DAOS experiments in the Moscow region, conducted in neighbouring fields for 74 and 76 years. Treatments included absolute control, application of organic, mineral, organic and mineral fertilizers at increasing rates. One of the experiments showed the growth of C stocks $12 \%$ in the layer $0-20 \mathrm{~cm}$ in the first 20 years in treatments with mineral fertilization, and $17 \%$ with the additional application of manure in an average annual rate of $10 \mathrm{Mg} \cdot \mathrm{ha}^{-1}$. The accumulation of $\mathrm{C}$ allowed increasing its stock by $18-25 \%$. Still, with the subsequent decline in crop rotation productivity, there was a loss of part of the previously accumulated C. In another experiment, at close values of annual $\mathrm{C}$ input, there was a loss of initial $\mathrm{C}$ stock due to the history of land use. The crop rotation adjustment provided a 3-8\% increase of soil $\mathrm{C}$ in the $0-20 \mathrm{~cm}$ layer in the first 20 years after introduction but was insufficient to match the "4 ppm" initiative. In the long term, the organic fertilizer system had an advantage over the mineral one in ensuring the stability of organic $\mathrm{C}$ stocks in the arable layer. However, the management of $\mathrm{C}$ sequestration was complicated in the non-equilibrium state of the carbon system "plant residues-organic fertilizer-soil".
\end{abstract}

\section{Introduction}

Global climate warming is one of the most pressing challenges of modern times, threatening the stability of the environment; mitigating climate change consequences is one of the Objectives of sustainable development [1]. Previously, the potential for mitigating climate change was mainly linked to the reduction of industrial greenhouse gas emissions into the atmosphere. However, in recent years there has been increasing attention to the role of agriculture in the carbon cycle, and the most powerful potential is the management of soil carbon reserves [2]. At the 21st Conference of the Parties to the UN Framework Convention on Climate Change in 2017, the "4 ppm" initiative was launched, whereby the annual increase in carbon reserves in all soils used in agriculture by $0.4 \%$ in the $0-40 \mathrm{~cm}$

\footnotetext{
*Corresponding author: prokopyeva@ecfs.msu.ru
} 
layer will double the reduction of greenhouse gas emissions into the atmosphere [2]. The initiative received the rapid and vigorous support of specialists in the field of soil science and agriculture [3]. At the same time, some experts expressed doubts about the technical feasibility of the project $[4,5]$. Among the obvious reasons was called costliness of measures, lack of organic fertilizers, and the fact that in humus-rich soils, increasing organic carbon reserves requires greater effort and cost than in the originally low-humus soils. Many of the questions were removed during the subsequent discussion, which showed that the obstacles were not of principle [6]. Currently, there is active work around the world to assess the potential for agricultural soils under different management in specific regions to sequester atmospheric carbon (see, for example, [7]). Despite the fact, that Russia is the leader in reducing greenhouse gas emissions into the atmosphere, reducing them from 1990 to 2014 by almost 17 million tons annually [8], participation in the "4 ppm" initiative will allow to additionally contribute to reducing the negative effects of climate change and to increasing soil fertility at the same time [9]. Previously in Russia, the participation of soils in the carbon cycle was assessed both within the frames of experimental farms and nationally $[10,11]$. Due to the new challenges of the "4 ppm" initiative, the most accurate forecast of the carbon balance in soils is required, which is possible based on simulations based on the available data of long-term field experiments. Evaluation and modelling of carbon dynamics showed that at specific crop rotation and fertilizer rates, it was possible to achieve an annual increase in carbon reserves by more than 4\%o [12]. At the same time, the model showed good convergence with real results, which allows using the obtained models to predict carbon dynamics in the future. In this work, we set ourselves the task of assessing the potential of carbon sequestration in the period 1935-2011 in two long-term field experiments in the Moscow region conducted on typical soils. Based on the analysis of carbon dynamics, we expect to identify the potential possibility and duration of carbon sequestration by agricultural soils of the Moscow region and recommend optimal management practices for increasing carbon reserves by more than $4 \%$ per year.

\section{Objects and Methods}

Objects of research are two long-term field experiments of the Dolgoprudny Agrochemical Experiment Station (Dolgoprudny, Moscow Region), included in the Geographic network of field experiments with fertilizers (Geoset). Soil is sod-medium podzolic heavy loam on cover loam.

Experiment 3 "Efficiency of increasing rates of mineral fertilizers" was launched in 1937. The site was in long-term agricultural use prior to the experiment establishment. Four-field feed crop rotation of fodder beets-spring wheat-potato-oats in 1965 was changed to three-field with two fields of row crops (beet, potato, sunflower) and a field of barley, held until 2011 in three fields. The original carbon content in the layer 0-20 cm was 1.0$1.1 \%$, which corresponded to the $\mathrm{C}$ stock $28.6-28.8 \mathrm{Mg} \cdot \mathrm{ha}^{-1}$. During the period of the experiment, the organic carbon content of the layer $0-20 \mathrm{~cm}$ was determined eight times. For modelling we have used the data of the first field on the following treatments: absolute control without fertilizers (control), NPK 1.5 rates with farmyard manure (FYM) application $40 \mathrm{Mg} \cdot \mathrm{ha}^{-1}$ per rotation $\left(20 \mathrm{Mg} \cdot \mathrm{ha}^{-1}\right.$ for potatoes and $20 \mathrm{Mg} \cdot \mathrm{ha}^{-1}$ for beet) $(1,5 \mathrm{NPK}+\mathrm{FYM})$, NPK 3 rates without manure application (3NPK), NPK 3 rates against the background of FYM application (3NPK+FYM). The unit rate of mineral fertilizers for the first seven rotations was $\mathrm{N}_{60} \mathrm{P}_{75} \mathrm{~K}_{90}$ for potatoes, $\mathrm{N}_{80} \mathrm{P}_{100} \mathrm{~K}{ }_{120}$ for beet and $\mathrm{N}_{30} \mathrm{P}_{38} \mathrm{~K}_{45}$ for cereal, further adjusted for $\mathrm{PK}$, remaining unchanged for $\mathrm{N}$.

Experiment 4 "Efficiency of ballast and concentrated forms of mineral fertilizers" was launched in 1933. The site was under natural forest vegetation until 1925, prior to the 
experiment fertilizers were not introduced. Five-field crop rotation clover - winter rye potato - fodder beet - oats with clover under sowing are held in 5 fields. In 1978, from $10^{\text {th }}$ rotation, the crop rotation changed to four-field: clover - winter wheat - potato barley with clover under sowing. The original carbon content in the layer $0-20 \mathrm{~cm}$ was 1.0 $1.3 \%$, which corresponded to the $\mathrm{C}$ stock of $30.3-32.4 \mathrm{Mg} \cdot \mathrm{ha}^{-1}$. The scheme to monitor its content was similar to the previous experiment. Data from 1935-2011 of the first field for the following treatments were used: absolute control; manure $50 \mathrm{Mg} \cdot \mathrm{ha}^{-1}$ per rotation (from 1978 - $40 \mathrm{Mg} \cdot \mathrm{ha}^{-1}$ (FYM), NPK - treatment with ballast fertilizers — ammonium sulfate, simple superphosphate, potassium salt (NPK1) and equivalent application of diammonium phosphate and potassium chloride (NPK2). For row crops and winter wheat $\mathrm{N}_{90} \mathrm{P}_{90} \mathrm{~K}_{90}$ was applied, from the $10^{\text {th }}$ rotation for potatoes $-\mathrm{N}_{90} \mathrm{P}_{90} \mathrm{~K}{ }_{120}$, for oats and row crops $-\mathrm{N}_{45} \mathrm{P}_{45 \mathrm{~K}}$ ${ }_{45}$, barley $-\mathrm{N}_{60} \mathrm{P}_{80} \mathrm{~K}_{80}$. Some experimental data on the field experiments are summarized in the monograph [13].

Rothamsted model RothC version 26.3 was used to study the dynamics of soil organic carbon (SOC), which investigates the cycle of organic substances in the arable layer of automorphic mineral soils with a monthly step, taking into account the effect of soil type, temperature, soil moisture and vegetation cover [14]. In the RothC model, total C stock is divided into five pools: decomposable plant material DPM, resistant plant material RPM, microbial biomass BIO, humified HUM and inert IOM organic matter having different mineralization rates described by first-order equations. To launch the model, a database of EuroSOMNET standard was constructed - the European Network of Field Experiments for the study of soil organic matter, which includes the above Geoset experiments [15]. The monthly $\mathrm{C}$ inputs in the soil were calculated using yield dependency [16] and manure quality reference data. The initial carbon distribution across the pools to run the model is modelled at steady state conditions. The content of the IOM pool was pre-calculated, according to [17]. After the IOM pool was calculated, plant inputs needed to achieve the measured soil $\mathrm{C}$ at the start of the experiments were estimated by running the model to steady-state using default plant inputs. For the DAOS 3 experiment, the default value of input $\mathrm{C}$ corresponded to $830-840 \mathrm{~kg} \cdot \mathrm{ha}^{-1}$, for DAOS $4-880-940 \mathrm{~kg} \cdot \mathrm{ha}^{-1}$. The RothC model was fitted against the control treatment, using the other treatments as independent to test the accuracy of the simulations. The initial steady-state RPM content was increased due to a proportionate reduction in HUM quantity and reduced $\mathrm{C}$ input with manure input.

The accuracy of simulations of the measured values in the field experiments was carried out based on the Modeval statistical evaluation model. It is software that calculates a set of indicators for adequate statistical analysis $[18,19]$.

\section{Results and Discussion}

Statistical evaluation of simulated results reveals a satisfactory fit to experimental data for all the treatments [19], for DAOS 4 the indicators reflect the best modelling accuracy. The root mean squared error (RMSE) showing the discrepancy between simulated and actual values in DAOS 4 was 3.56-7.74, and DAOS 3 - 5.94-10.66 (Table 1). For the four treatments of the DAOS 4 experiment, the correlation coefficient ( $r$ ) was between 0.82 and 0.90 . The value of simulation efficiency $(\mathrm{EF})$ in the four experiment treatments ranged from 0.51 to 0.73 (a maximum value of 1 ). In all treatments of the two experiments except for $1,5 \mathrm{NPK}+$ manure in DAOS3, a better description of experimental data is achieved by the model than by the mean of the experimental values, which is shown by the value of $C D>1$. 
Table 1.Statistical evaluation of modelling results by RothC DAOS 3 and DAOS 4 experiments

\begin{tabular}{|l|c|c|c|c|c|}
\hline Treatment & $\begin{array}{c}\text { Coefficient } \\
\text { of } \\
\text { correlation } \\
\text { (r) }\end{array}$ & $\begin{array}{c}\text { Root Mean } \\
\text { Squared } \\
\text { Error } \\
\text { (RMSE) }\end{array}$ & $\begin{array}{c}\text { Simulation } \\
\text { Efficiency } \\
\text { (EF) }\end{array}$ & $\begin{array}{c}\text { Coefficient of } \\
\text { Determination } \\
\text { (CD) }\end{array}$ & $\begin{array}{c}\text { Systematic } \\
\text { Error (M) }\end{array}$ \\
\hline \multicolumn{7}{|c|}{ DAOS 3 experiment } \\
\hline Control & 0.15 & 7.65 & -0.04 & 8.07 & 0.42 \\
\hline $\begin{array}{l}1.5 N P K+ \\
\text { FYM }\end{array}$ & 0.68 & 6.90 & -0.12 & 0.66 & -1.46 \\
\hline 3NPK & -0.24 & 10.66 & -1.31 & 1.08 & -1.15 \\
\hline $\begin{array}{l}\text { 3NPK + } \\
\text { FYM }\end{array}$ & 0.74 & 5.94 & 0.45 & 1.24 & -0.77 \\
\hline \multicolumn{7}{|l|}{} & DAOS 4 experiment & & \\
\hline Control & 0.90 & 7.60 & 0.71 & 2.88 & -0.15 \\
\hline FYM & 0.76 & 3.56 & 0.51 & 1.39 & 0.38 \\
\hline NPK1 & 0.86 & 6.43 & 0.73 & 1.75 & -0.12 \\
\hline NPK2 & 0.82 & 7.74 & 0.63 & 1.57 & 0.72 \\
\hline
\end{tabular}

Figure 1 shows the dynamics of carbon stocks based on model-calculated and experimental data. In the DAOS 3 experiment in the first 50 years (1937-1987), there is a consistent increase of the SOC stocks reaching maximum values of $37-39 \mathrm{Mg} \cdot \mathrm{ha}^{-1}$ by 1987 and then a slight decline for the last 20 years. Growth was most pronounced in the first twenty years, decreasing for treatments $3 \mathrm{NPK}+\mathrm{FYM}>1.5 \mathrm{NPK}+\mathrm{FYM}>\mathrm{NPK}$. At the same time, with increasing rates of mineral fertilizers on the background of manure, differences were not observed up to 1970 , by 1980 they were $1 \mathrm{Mg} \cdot \mathrm{ha}^{-1}$, and at present $-1.4 \mathrm{Mg} \cdot \mathrm{ha}^{-1}$. Carbon accumulation under mineral fertilization had the same tendency as in organomineral treatments, but carbon stocks were smaller by $2-4 \mathrm{Mg} \cdot \mathrm{ha}^{-1}$, minimal differences were observed in the $70-80 \mathrm{~s}$. At the same time, the interannual variation during the nearly steady state period was $4-5 \%$ of the SOC stock. A decrease replaced the gradual increase by the early ' $90 \mathrm{~s}$. Still, SOC losses in comparison with the initial stock for treatments with fertilization did not occur compared to control.

For DAOS 4, the initial carbon stocks gradually decreased to $22-27 \mathrm{Mg} \cdot \mathrm{ha}^{-1}$ in the first 30 years of the experiment. In the control and treatments with the mineral fertilizers, the rate of decrease was higher than in the organo-mineral treatment, where the carbon stock stabilized by the $60 \mathrm{~s}$. 


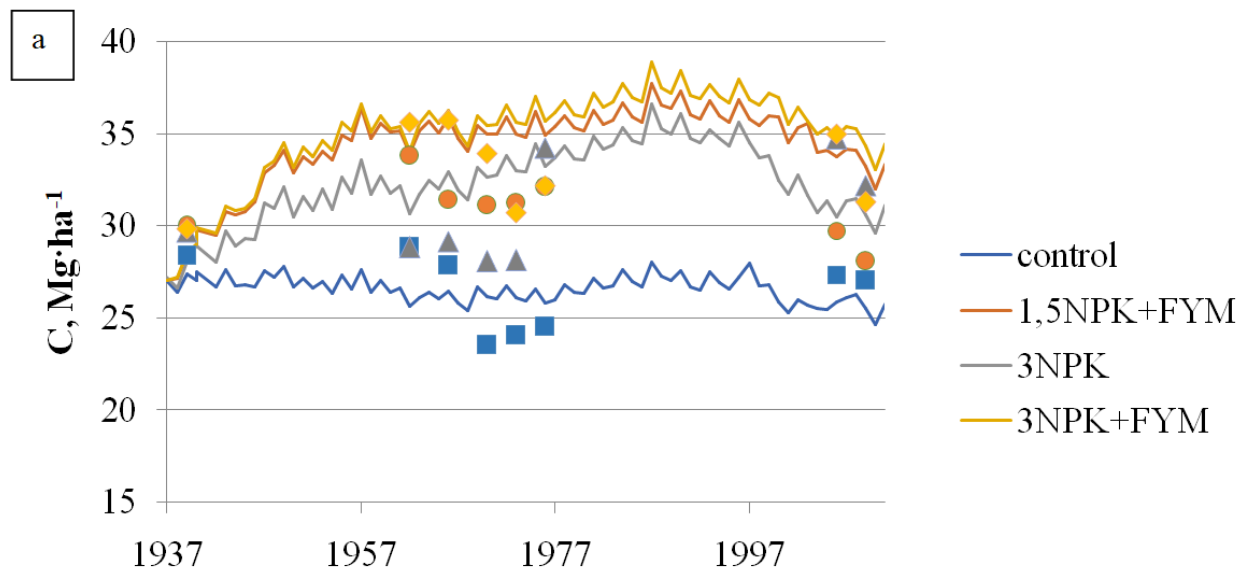

Year

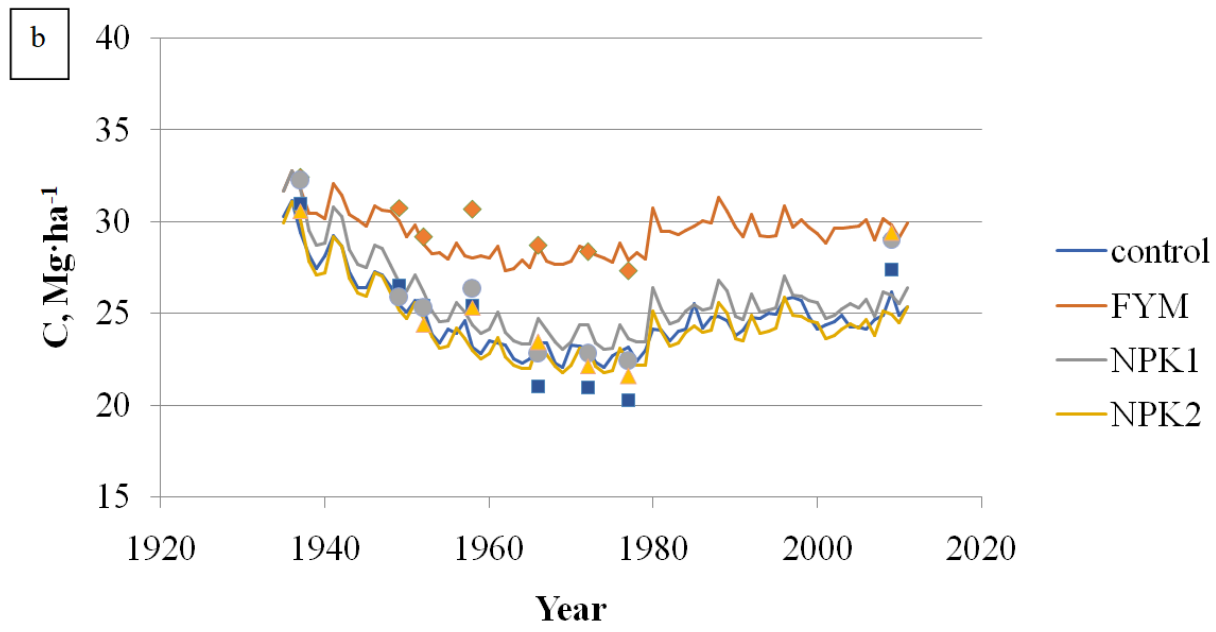

Fig. 1. Dynamics of SOC stocks $\left(\mathrm{Mg} \cdot \mathrm{ha}^{-1}\right)$ calculated by the RothC model (line) and determined experimentally (points) in the arable layer of soil of the long-term experiment: a - DAOS $3, \mathrm{~b}-$ DAOS 4.

Subsequently, there was a fluctuation around the new steady state until the 1980s, with the interannual variation of $5-6 \%$ of the SOC stock, with some growth in recent years. By 2011, all treatments other than the manure application had not achieved the initial SOC stocks $\left(30 \mathrm{Mg} \cdot \mathrm{ha}^{-1}\right)$.

The results of the simulation allow estimating the required amount of annual $\mathrm{C}$ input into the soil, which allows maintaining its stock or provide additional sequestration.

To estimate annual carbon gains and losses, the pilot period of each experiment (74 years for DAOS 3 and 78 years for DAOS 4) was broken down into twenty years periods, according to 4 ppm calculations discussed in [20] and [3] (Table 2).

Using the results shown in Table 2 , it is possible to evaluate the average annual change in SOC stock in the arable layer depending on the average $\mathrm{C}$ input over 20 years periods of observations. RothC describes the dynamics of $\mathrm{C}$ based on first-order differential equations, so the dependence obtained using the model is linear:

$$
\text { for DAOS 3: } \Delta C=0.310 \text { Cinp }-0.430
$$


for DAOS 4: $\triangle C=0.135$ Cinp -0.289

where $\Delta C$ is the average annual change of SOC stocks in $0-20 \mathrm{~cm}$ layer, $\mathrm{Mg} \cdot \mathrm{ha}^{-1}$, Cinp is the average annual value of $\mathrm{C}$ input into the soil with plant residues and organic fertilizers, $\mathrm{Mg} \cdot \mathrm{ha}^{-1}$. To maintain SOC stock for the entire study period, an average of 1.39 $\mathrm{Mg} \cdot \mathrm{ha}^{-1}$ of C should be returned in the soil of DAOS 3 annually, $2.13 \mathrm{Mg} \cdot \mathrm{ha}^{-1}$ of $\mathrm{C}$ for DAOS 4. The annual increase of $4 \%$ will provide input of 1.74 and $3.02 \mathrm{Mg} \cdot \mathrm{ha}^{-1} \mathrm{C}$, respectively.

In both experiments, there is a tendency that the gain increases, and losses decrease in the line of organo-mineral fertilizers $>$ organic fertilizers $>$ mineral fertilizers $>$ control. In DAOS 3 treatments form the following series: $3 \mathrm{NPK}+\mathrm{FYM}>1.5 \mathrm{NPK}+\mathrm{FYM}>3 \mathrm{NPK}>$ control. In DAOS 4: $\mathrm{FYM}>\mathrm{NPK} 2>\mathrm{NPK} 1>$ control (Fig.1).

Table 2.Annual gain / loss and input of C, by experiment treatments

\begin{tabular}{|c|c|c|c|c|c|}
\hline \multirow{2}{*}{ Period } & \multicolumn{5}{|c|}{ Treatments of DAOS 3 experiment } \\
\cline { 2 - 6 } & \multicolumn{5}{|c|}{ Annual increase (loss), \%o/ C input, Mg ha ${ }^{-1}$} \\
\cline { 2 - 6 } & control & $1,5 \mathrm{NPK}+\mathrm{FYM}$ & $3 \mathrm{NPK}$ & 3NPK+FYM \\
\hline $1937-1957$ & $1.1 / 0.90$ & $17.2 / 2.07$ & $11.7 / 1.69$ & $17.7 / 2.13$ \\
\hline $1957-1977$ & $-2.9 / 0.88$ & $-1.3 / 1.83$ & $0.2 / 1.70$ & $-0.06 / 1.90$ \\
\hline $1977-1997$ & $3.8 / 1.02$ & $0.6 / 1.59$ & $1.2 / 1.54$ & $0.09 / 1.70$ \\
\hline $1997-2011$ & $-5.7 / 1.08$ & $-4.9 / 1.45$ & $-7.0 / 1.08$ & $-4.7 / 1.57$ \\
\hline \multirow{2}{*}{ Period } & & Treatments of DAOS 4 experiment \\
\cline { 2 - 6 } & & Annual increase (loss), \%o / C input, Mg $\cdot$ ha $^{-1}$ \\
\cline { 2 - 6 } & control & FYM & NPK1 & NPK2 \\
\hline $1935-1955$ & $-10.2 / 1.14$ & $-5.8 / 1.98$ & $-11.1 / 1.66$ & $-11.3 / 1.71$ \\
\hline $1955-1975$ & $-2.9 / 0.99$ & $-0.3 / 1.88$ & $-3.0 / 1.53$ & $-2.9 / 1.48$ \\
\hline $1975-1995$ & $4.9 / 1.26$ & $2.5 / 2.10$ & $4.8 / 1.88$ & $5.3 / 1.93$ \\
\hline $1995-2011$ & $-0.7 / 1.44$ & $0.1 / 2.09$ & $1.0 / 1.93$ & $1.3 / 2.06$ \\
\hline
\end{tabular}

The highest carbon input is typical for organic fertilizer treatments in all experiments, while the least is for the controls. Fertilization allows for a significant increase in $\mathrm{C}$ input to the soil compared to the controls. Differences in the SOC dynamics of the controls and treatments with fertilizers may be due to both the relatively lower amount of plant residues and the lower ratio of underground and overground biomass, which is taken into account in Levin's equations [16].

In the DAOS 3 experiment, there is a significant annual increase of $12-17 \%$ in the first twenty years in all treatments with fertilization, which is due to 2-2.5 times higher $\mathrm{C}$ input compared to the period before experimentation. The control treatment for this period maintains the initial $\mathrm{C}$ stock while keeping the initial level of $\mathrm{C}$ input with plant residues. 
With an increase of $18-25 \%$ of SOC stocks for the first twenty years after that with steady state (3 NPK) or some decrease (organo-mineral treatments), C inputs can only support the new SOC level. The change in crop rotation did not increase $\mathrm{C}$ input in the third period but was sufficient to sustain the achieved SOC stocks. However, when the average annual C input dropped to $1.1-1.4 \mathrm{Mg} \cdot \mathrm{ha}^{-1}$ in 1997-2011, this resulted in an annual loss of 5-7 \%o from previously accumulated SOC stocks.

In the DAOS 4 experiment, it is possible to highlight the most favourable period of increase SOC stocks from 1975 to 1995 , while significant losses are recorded in the initial stages. In the first twenty years, $28-34 \%$ of the original stocks are lost; the average annual loss is $11 \%$ o for treatments with mineral fertilization. In FYM treatment, they are twice less due to the periodic application of organic fertilizers. At the same time, the average annual C input to the soil increases by 1.8-2.2 times compared to the previous period.

A more detailed analysis of $\mathrm{C}$ dynamics in this experiment compared with DAOS 3, where close values of $\mathrm{C}$ input were observed during the same period, was given earlier [12]. The main difference in $\mathrm{C}$ dynamics is due to the different history of land use in closely located plots. After forest cleaning, the organic matter of DAOS 4 soil is dominated by relatively less stable pools, which are not replenished during agricultural use, which causes the existence of a non-equilibrium state. An additional C input of $150-470 \mathrm{~kg} \cdot \mathrm{ha}^{-1}$ of $\mathrm{C}$ is required annually to maintain the baseline stocks, which is not achieved in any of the treatments considered. However, with a 5-15\% decrease in C input in the period 1957-1977 compared to the first one, the drop decreased significantly: the annual loss was $3 \%$ from previously accumulated SOC stocks for treatments with mineral nutrition, and in the FYM treatment the $\mathrm{C}$ stock stabilized at $27-28 \mathrm{Mg} \cdot \mathrm{ha}^{-1}$.

The change of crop rotation in the third period of the experiment allowed to increase the $\mathrm{C}$ input to $1.88-2.1 \mathrm{Mg} \cdot \mathrm{ha}^{-1}$ annually, with sequestration of 5\% SOC on mineral and $2.5 \%$ on the organic treatment. With this, since the 4 per mille initiative considers a layer of 0-40 $\mathrm{cm}$, the absolute increase only in the upper horizon should be higher than $4 \%$. According to [5] long-term experiments with Rothamsted fertilizers, it was proposed to use the value $>7 \%$ in the layer $0-23 \mathrm{~cm}$ as equivalent to $4 \%$ in the upper $40 \mathrm{~cm}$ layer. In this case, the accumulation of $\mathrm{C}$ in the third period remains below the normative figures. By the end of this period, SOC stock reached $25 \mathrm{Mg} \cdot \mathrm{ha}^{-1}$ on mineral nutrition, and $30 \mathrm{Mg} \cdot \mathrm{ha}^{-1}$ on organic nutrition; it led to a new steady state when in maintaining the level of $\mathrm{C}$ input into the soil in the last period of observation no further significant changes occurred.

Speaking about the sustainability of the sequestration process, in the DAOS 3 experiment the $3 \mathrm{NPK}+\mathrm{FYM}$ treatment differs in the higher rate of accumulation in the first period and a lower rate of loss in the fourth compared to $3 \mathrm{NPK}$. Increased C input was due to additional $\mathrm{C}$ input with manure. Compared to this, the $1.5 \mathrm{NPK}+\mathrm{FYM}$ treatment also proved to be more stable in the long term, which did not exclude losses, for example, in the second period. Similar in both experiments with the application of organic fertilizers is that the rates of loss and accumulation do not change as dramatically as in mineral treatments, both when accumulation or losses prevail. As a result, in absolute values over the entire study period, they are preferable, even if they do not reach the accumulation of $4 \%$.

\section{Conclusions}

The study of the possibility of long-term $\mathrm{C}$ sequestration by heavy-loamy sod podzolic soils showed that the optimization of the fertilizer system leading to a steady increase in the $\mathrm{C}$ input in the soil can ensure the accumulation of $\mathrm{C}$ in the upper layer of $4 \mathrm{ppm}$ quantity and higher in the first 20 years, the gain is finite, and the accumulated $\mathrm{C}$ can be quickly lost when crop rotation productivity is reduced. The ability to manage $\mathrm{C}$ accumulation depends on the field history of land use and can be traced over more than 20 years. Timely 
adjustment of crop rotation is also a significant factor that can ensure consistent $\mathrm{C}$ accumulation over a long period. Organic and organo-mineral fertilizer systems detect an advantage over mineral ones in ensuring the stability of organic $\mathrm{C}$ reserves management in the arable layer.

\section{Acknowledgement}

The study was conducted as part of the Horizon 2020 Coordination of International Research Cooperation on soil Carbon Sequestration in Agriculture (CIRCASA) project. Financial support for the research was received within the framework of the project "Management of the atmospheric carbon sequestration in arable soils of Russia" of the Federal Task Program "Research and development in priority areas of development of the scientific and technological complex of Russia for 2014-2020." Unique Project ID: RFMEFI61618X0105.

\section{References}

1. J. D. Sachs, The Lancet, 379(9832), 2206-2211 (2012)

2. J.F. Soussana, S. et.al., Soil and Tillage Research, 188,3-15 (2019)

3. B.Minasny, el.al., Soil carbon 4 per mille,Geoderma, 292, 59-86(2017)

4. P. Baveye, J. Berthelin, D. Tessier, and G. Lemaire, Geoderma, 309, 118-123 (2018)

5. P. Poulton, J. Johnston, A. Macdonald, R. White, and D. Powlson, Global Change Biology, 24, 2563-2584 (2018)

6. C. Chenu, D. A. Angers, P.Barré, D. Derrien, D. Arrouays, and J. Balesdent, Soil and Tillage Research, 188, 41-52 (2019)

7. M. Wiesmeier, S. Mayer, J. Burmeister, R. Hübner, and I. Kögel-Knabner, Geoderma, 369, 114333, (2020)

8. M. Kang, W.Zhao, L.Jia, Y.Liu, Chinese Geographical Science, 1-18 (2020)

9. A.L. Ivanov, V.S. Stolbovoy,Dokuchaev Soil Bulletin, 98, 185-202, (2019)

10. V.A. Romanenkov, et.al. Reg. Environ. Change, 7, 93-104 (2007)

11. V. Stolbovoy, A. Ivanov, Carbon balance in soils of Northern Eurasia, Soil Carbon, Progress in Soil Science, 381-390 (Springer, Switzerland, 2014)

12. V. Romanenkov, et.al., Geoderma Regional, 17(e00221), 1-10(2019).

13. A.D. Khlystovsky,Soil fertility with long-term use of fertilizers and lime, 192(Moscow: Nauka, 1992)

14. K. Coleman, D.S. Jenkinson, RothC -26.3 - a model for the turnover of carbon in soil, Evaluation of soil organic matter models using existing long-term datasets. Proceedings of the NATO Advanced Research workshop. NATO ASI Series I. Berlin: Springer Verlag, 38, 237-246, (1996)

15. U. Franko, et.al., Computers and Electronics in Agriculture, 33, 233-239 (2002)

16. F.I. Levin, Agrochemistry, 8, 36-42 (1977)

17. P. Falloon, P. Smith, K. Coleman, S. Marshall,Soil Biol. Biochem, 30,1207-1211 (1998)

18. J.U. Smith, P. Smith, Addiscott, Evaluation of soil organic matter models using existing, long-term datasets NATO ASI Series I, 38, 181-200(Springer-Verlag, Berlin, 1996)

19. P. Smith, J.U. Smith, Powlson et al.,Geoderma, 81,153-225(1997)

20. A. Chabbi, J. Lehmann, P. Ciais, H.W. Loescher, M.F. Cotrufo, A. Don, M. SanClements, L. Schipper, et al., Nature Climate Change, 7, 307-309 (2017)https://doi.org/10.1038/nclimate3286 